\title{
Organochlorine pesticide exposure as a risk factor for breast cancer in young Indian women: A case-control study
}

\author{
Navneet Kaur, Srikant K Swain, Basudev D Banerjee',Tusha Sharma',Thammineni Krishnalata'
}

\begin{abstract}
Background: Incidence rates of breast cancer are showing an increasing trend in young women ( $\leq 40$ years) in India. Risk for breast cancer in this age group can be attributed only partially to various known risk factors. Environmental exposure to organochlorine (OC) compounds has been identified as a potential risk factor. However, the possible role of OC compounds in increasing breast cancer risk in young women has not been explored.This case-control study was planned with the objectives to assess the serum levels of OC compound in a North Indian population of young women. Materials and Methods: Forty-two patients of breast cancer $\leq 40$ years age and 42 age-matched controls were evaluated for exposure to OC compounds by performing assays in blood samples for pesticides such as dichlorodiphenyltrichloroethane (DDT) and its metabolites DDD and DDE; dieldrin; aldrin; methoxychlor, heptachlor; $\alpha$-endosulfan; $\beta$-endosulfan; and hexachlorocyclohexane and its isomers $(\alpha, \beta$, and $\gamma)$. Results: Young women with breast cancer were found to have significantly higher serum levels of all the OC compounds except aldrin, p, p' DDT, and methoxychlor. Conclusions: Exposure to OC pesticides could be an important modifiable risk factor for breast cancer, especially in younger women.
\end{abstract}

Key words: Breast cancer, organochlorine compounds, risk factors, young women

\section{Introduction}

Breast cancer incidence in India has been increasing steadily in the last 30 years, and currently, it is the most common cancer among Indian women, with age-adjusted incidence rate of $25.8 / 100,000$ women. ${ }^{[1,2]}$ Younger women ( $\leq 40$ years) constitute about $11 \%-31 \%$ of all breast cancer cases in India. ${ }^{[3-5]}$ Further, recent data suggest a trend of increasing rates of breast cancer in younger women with annual percentage change (APC) ranging from $1 \%$ to $4.24 \%$ in $15-34$ years' age group, as compared to APC of $0.37 \%-2.97 \%$ in $35-44$ years' age group and $0.53 \%-2.64 \%$ in patients $>64$ years. ${ }^{[6,7]}$ Higher rates of breast cancer in younger women have also been reported from other South Asian countries. ${ }^{[8,9]}$

A number of risk factors have been identified for breast cancer, such as early age of menarche, late menopause, nulliparity, delayed first child birth, reduced duration of breastfeeding, use of oral contraceptives and hormone replacement therapy, family history of breast/ovarian cancer, history of previous breast biopsy, increased body mass index (BMI), and consumption of animal products, alcohol, etc. ${ }^{[2,5,10]}$ However, these factors do not address a considerable portion of the risk, especially in women who are young. Besides, in Indian women, the risk factor profile is different from their Western counterparts, as early first childbirth, multiparity, and breastfeeding are social norms and the use of oral contraceptives and hormone replacement therapy is low. ${ }^{[5,10,11]}$ Inherited/familial breast cancer accounts for $5 \%-10 \%$ of cases. ${ }^{[2,5,11]}$ Rising rate of breast cancer in India is being attributed to westernization of lifestyles. Yet, the Western population themselves who have the same risk factors do not have onset at younger ages. Hence, there might be a role of environmental factors, which is yet to be explored.

Environmental pollution due to the use of pesticides has been reported to play a role in increasing the risk for various cancers. ${ }^{[12]}$ Among these, the role of estrogenic-organochlorine (OC) compound pesticide has been evaluated for their potential role as a risk factor for breast cancer. ${ }^{[13]} \mathrm{A}$ number

\begin{tabular}{|l|}
\hline Access this article online \\
\hline Quick Response Code: \\
\\
Website: www.sajc.org \\
\hline DOI: $10.4103 /$ sajc.sajc_427_18 \\
\hline
\end{tabular}

Departments of Surgery and 'Biochemistry, UCMS and GTB Hospital, Delhi, India

Correspondence to: Prof. Navneet Kaur, E-mail:dr_navkaur@hotmail.com of epidemiological studies, reported from different parts of the world, have shown variable results. ${ }^{[14-17]}$ However, very limited data is available from South Asian countries where use of these pesticides is still rampant. ${ }^{[18,19]}$ Hence, we planned this study to evaluate the risk factor profile, with special focus on the potential role of xenoestrogens, by the estimation of estrogenic OC compound levels in the blood samples of women with breast cancer $\leq 40$ years of age.

\section{Materials and Methods}

This hospital-based, case-control study was conducted in the departments of surgery and biochemistry, at an academic center in Delhi, North India, from January 2015 to April 2016. The study protocol was approved by the institutional ethics committee. Forty-two biopsy-proven women with carcinoma breast aged $\leq 40$ years were included in the study after obtaining their informed consent. For each case, an age-matched healthy woman, free of any breast or gynecological pathology, was recruited as a control.

A predesigned pro forma was used to record information about demographic and clinical details. Information was also collected about various known and potential risk factors such as family history of breast/ovarian cancer, age at menarche, age at first child birth, total duration of breastfeeding, number of abortions, any history of a breast biopsy, food habits, addictions, and socioeconomic status.

Estimation of serum levels of organochlorine compounds Estimation of serum levels of estrogenic OC compounds including hexachlorocyclohexane ( $\mathrm{HCH})-\alpha, \beta, \gamma$, heptachlor, dichlorodiphenyltrichloroethane (DDT), DDE, DDD and endosulfan-1 and endosulfan-2, aldrin, dieldrin, and methoxychlor was done using gas chromatography analysis.

Statistical analysis

Descriptive analysis was used for evaluating the demographic and clinical characteristics. Unpaired $t$-test and Chi-square test were

This is an open access journal, and articles are distributed under the terms of the Creative Commons Attribution-NonCommercial-ShareAlike 4.0 License, which allows others to remix, tweak, and build upon the work non-commercially, as long as appropriate credit is given and the new creations are licensed under the identical terms.

For reprints contact: reprints@ @medknow.com

How to cite this article: Kaur N, Swain SK, Banerjee BD, Sharma T, Krishnalata T. Organochlorine pesticide exposure as a risk factor for breast cancer in young Indian women: A case-control study. South Asian J Cancer 2019;8:212-4. 
used to evaluate the significance of difference between the two groups as appropriate. Mann-Whitney U-test was used to test the significance of association of serum levels of OC compound with breast cancer. Odds ratio for various risk factors was calculated by using univariate logistic regression analysis.

\section{Results}

\section{Demographic and clinical characteristics of the study population}

The mean age of breast cancer patients and control group was 35.79 years and 36.31 years, respectively. The most common stage of presentation was Stage II (36\%), followed by locally advanced breast cancer (Stage III, 31\%) and advanced metastasis disease $(10 \%)$. The most common histological type was invasive ductal carcinoma $(78.6 \%)$ and $37.5 \%$ had histological Grade-2 disease. In our study, $60 \%$ of patients were estrogen receptor $+\mathrm{ve}, 34.3 \%$ were progesterone receptor $+\mathrm{ve}$, and $28.57 \%$ had triple-negative receptor status.

\section{Risk factor profile of the study population}

The prevalence of various known risk factors in breast cancer patients was very low. None of the patients were nullipara. The mean age at first child birth was $20.5 \pm 3$ years, and the average duration of breastfeeding was $5.80 \pm 4.04$ years. Only one patient had a strong family history of breast cancer and two had a history of biopsy for benign breast disease. Almost $80 \%$ were vegetarian, and none reported prolonged use of oral contraceptives. However, a statistically significant difference was noted in the age of menarche between the cases (12 \pm 1 years) and controls $(13 \pm 1$ years) $(P=0.002)$ and also in BMI between the two groups (cases [25.08 \pm 2.98 ], controls $[23.06 \pm 2.64][P=0.001])$.

\section{Organochlorine pesticide exposure in the study}

\section{population}

Analysis of the serum levels of various isomers and metabolites of OC pesticides showed that the $\alpha-, \beta-, \gamma-\mathrm{HCH}$; heptachlor; DDE; endosulfan-1 and endosulfan-2; and dieldrin isomer levels were significantly higher in patients with carcinoma breast than controls [Table 1]. On further analysis, odds ratios were found to be significant for $\beta-\mathrm{HCH}$, heptachlor, dieldrin, and $\mathrm{p}$, p' DDE, at $4.15,3.14,11.74$, and 8.81 , respectively [Table 2].

\section{Discussion}

OC pesticides (OCPs) are synthetic pesticides widely used worldwide. They belong to the group of chlorinated hydrocarbon derivatives, which have vast application in the chemical industry and agriculture. These compounds are known for their high toxicity, slow degradation, and bioaccumulation. Even though many of the compounds were banned in developed countries in the 1970s, insecticides such as DDT, $\mathrm{HCH}$, aldrin, and dieldrin are still under use in developing countries of Asia. ${ }^{[2]}$ The most commonly used pesticide in agricultural practice is DDT, which is moderately hazardous, with high persistence and a half-life of 2-15 years. OCPs can enter the environment after pesticide applications, polluted waste discarded into landfills, and discharges from industrial units that synthesize these chemicals. Food items such as meat, fish, poultry, and dairy products serve as the main sources of exposure to these pesticides through diet. ${ }^{[21]}$ These pesticides cause neurological damage and endocrine disorders and are reported to increase the risk of hormone-related cancers including breast, prostate, stomach, and lung cancers. ${ }^{[12,14]}$ Further, individuals with lower age group are reported to have higher risk of health hazards due to pesticides than those in higher age group. ${ }^{[19]}$

The present study found a statistically significant association between exposure to OC pesticides and risk of carcinoma breast in young women. Significantly higher blood levels of $\alpha-, \beta-, \gamma-\mathrm{HCH}$; heptachlor; DDE; endosulfan-1; dieldrin; and endosulfan-2 were found in breast cancer patients. However the odds ratio for breast cancer were found significant only with $\beta-\mathrm{HCH}$, heptachlor, DDE, and dieldrin. These results are consistent with many other reports, mostly from countries where exposure to OCPs continues till date. ${ }^{[22-24]}$ Høyer et al. in their study in Danish population reported that women with increased level of serum dieldrin had an increased risk of breast cancer. ${ }^{[25]}$ Arrebola et al. from Tunisia reported that $\beta-\mathrm{HCH}$, heptachlor, hexachlorobenzene, and p, p' DDE were positively associated with breast cancer risk. ${ }^{[26]}$ However, many case-control studies published from Europe, Canada, and North America failed to find any significant association. ${ }^{[16,17,27]}$ This is probably because exposure to OCPs is low in these populations overall, and hence can not be a significant contributor to breast cancer risk. Based on an exhaustive review of epidemiological and laboratory studies, Grey JM et al. (2017) in their report concluded that an overall comparison of the association between disease risk and DDT use in developed countries (where DDT has been banned for several decades) and in developing countries (where DDT

Table 1: Organochlorine pesticide levels in blood samples in the study population

\begin{tabular}{|c|c|c|c|}
\hline \multirow[t]{2}{*}{ Group } & \multicolumn{2}{|c|}{ Median (IQR), mean \pm SD } & \multirow[t]{2}{*}{ Significance $P$ (Mann-Whitney) } \\
\hline & Carcinoma & Control & \\
\hline$\alpha-\mathrm{HCH}$ & $3.73(3.14-4.39), 4.14 \pm 1.50$ & $3.22(2.29-3.97), 3.61 \pm 1.51$ & 0.027 \\
\hline$\beta$-HCH & $6.92(6.26-7.82), 7.02 \pm 1.29$ & $4.30(3.43-5.52), 4.49 \pm 1.22$ & 0.000 \\
\hline$\gamma-\mathrm{HCH}$ & $2.41(1.88-3.17), 2.61 \pm 0.92$ & $2.16(1.56-3.18), 2.32 \pm 1.01$ & 0.034 \\
\hline Heptachlor & $5.61(3.53-8.85), 6.65 \pm 3.56$ & $3.21(2.19-3.76), 3.12 \pm 1.00$ & 0.000 \\
\hline Aldrin & $2.44(1.38-4.21), 2.83 \pm 2.06$ & $2.01(1.00-4.13), 2.62 \pm 2.05$ & 0.552 \\
\hline Dieldrin & $2.10(1.57-2.51), 2.17 \pm 0.75$ & $1.21(1.06-1.36), 1.30 \pm 0.54$ & 0.000 \\
\hline Endo I & $1.52(1.23-2.14), 1.66 \pm 0.54$ & $1.35(1.12-1.61), 1.49 \pm 0.58$ & 0.047 \\
\hline Endo II & $1.37(1.02-2.38), 1.71 \pm 0.85$ & $1.23(0.68-2.06), 1.38 \pm 0.84$ & 0.043 \\
\hline $\mathrm{p}, \mathrm{p}$ ' DDE & $5.48(4.81-6.65), 5.84 \pm 1.55$ & $3.53(2.87-4.00), 3.49 \pm 0.89$ & 0.000 \\
\hline $\mathrm{p}, \mathrm{p}^{\prime} \mathrm{DDT}$ & $4.39(3.85-5.12), 4.69 \pm 1.31$ & $4.11(3.62-4.57), 4.42 \pm 1.38$ & 0.122 \\
\hline $\mathrm{p}, \mathrm{p}^{\prime} \mathrm{DDD}$ & 1.64 (1.42-1.94), $1.73 \pm 0.38$ & 1.49 (1.32-1.80), $1.63 \pm 0.46$ & 0.053 \\
\hline Methoxychlor & $2.93(2.51-3.24), 2.96 \pm 0.65$ & $2.78(2.54-3.10), 2.78 \pm 0.46$ & 0.199 \\
\hline
\end{tabular}

$\mathrm{HCH}=$ Hexachlorocyclohexane, $\mathrm{IQR}=$ Interquartile range, $\mathrm{SD}=$ Standard deviation 
Table 2: Correlation of oral contraceptives with risk of breast cancer in young women

\begin{tabular}{lccc}
\hline Organochlorine pesticides & OR & $95 \%$ CI & $P$ \\
\hline$\alpha-\mathrm{HCH}$ & 1.275 & $0.940-1.730$ & 0.118 \\
$\beta-\mathrm{HCH}$ & 4.153 & $2.355-7.326$ & 0.000 \\
$\gamma$-HCH & 1.380 & $0.871-2.188$ & 0.170 \\
Heptachlor & 3.138 & $1.762-5.587$ & 0.000 \\
Aldrin & 1.052 & $0.851-1.299$ & 0.641 \\
Dieldrin & 11.739 & $3.927-35.092$ & 0.000 \\
Endo I & 1.771 & $0.793-3.953$ & 0.163 \\
Endo II & 1.598 & $0.944-2.705$ & 0.081 \\
p, p' DDE & 8.814 & $3.434-22.622$ & 0.000 \\
p, p' DDT & 1.163 & $0.839-1.613$ & 0.364 \\
p, p' DDD & 1.724 & $0.604-4.920$ & 0.309 \\
Methoxychlor & 1.828 & $0.782-4.272$ & 0.163 \\
\hline
\end{tabular}

$\mathrm{OR}=$ Odds ratio, $\mathrm{CI}=$ Confidence interval, $\mathrm{HCH}=\mathrm{Hexachlorocyclohexane}$

use is still prevalent) supports the premise that exposures to DDT are associated with an increased risk of breast cancer. ${ }^{[13]}$

\section{Conclusions}

Exposure to OCPs could be contributing to an increasing incidence of breast cancer in younger women in India.

Limitation

The sample size in this study is small and hence underpowered to ascertain clinical significance of these findings.

Financial support and sponsorship

Nil.

\section{Conflicts of interest}

There are no conflicts of interest.

\section{References}

1. GLOBOCAN 2012: Estimated Cancer Incidence, Mortality and Prevalence Worldwide in 2012. GLOBOCAN, Section of Cancer Surveillance. IARC; 2012. Available from: http://www.globocan.iarc.fr/Pages/fact_sheets_ cancer.aspx?cancer=breast. [Last accessed on 2017 Apr 11].

2. Malvia S, Bagadi SA, Dubey US, Saxena S. Epidemiology of breast cancer in Indian women. Asia Pac J Clin Oncol 2017;13:289-95.

3. Varughese AA, Poothiode U, Manjula VD. Descriptive study on selected risk factors and histopathology of breast carcinoma in a tertiary care centre in Kerala, India with special reference to women under 40 years old. Asian Pac J Cancer Prev 2015;16:181-4.

4. Thangjam S, Laishram RS, Debnath K. Breast carcinoma in young females below the age of 40 years: A histopathological perspective. South Asian J Cancer 2014;3:97-100.

5. Surakasula A, Nagarjunapu GC, Raghavaiah KV. A comparative study of pre- and post-menopausal breast cancer: Risk factors, presentation, characteristics and management. J Res Pharm Pract 2014;3:12-8.

6. Murthy NS, Agarwal UK, Chaudhry K, Saxena S. A study on time trends in incidence of breast cancer - Indian scenario. Eur J Cancer Care (Engl) 2007; 16: 185-6.

7. Available from: http://www.breastcancerindia.net/statistics/stat_ global.html. [Last accessed on 2017 Jan 25].

8. Agarwal G, Pradeep PV, Aggarwal V, Yip CH, Cheung PS. Spectrum of breast cancer in Asian women. World J Surg 2007;31:1031-40.

9. Thapa B, Singh Y, Sayami P, Shrestha UK, Sapkota R, Sayami G. Breast cancer in young women from a low risk population in Nepal. Asian Pac $J$ Cancer Prev 2013; 14:5095-9.

10. Vinod R, Ganesan P. Risk Factors for Breast Cancer in India: An Index Case-Control Study. New Delhi: INDOX Cancer Research Network; 2011.

11. Kaur N, Attam A, Saha S, Bhargava SK. Breast cancer risk factor profile in Indian women. JIMSA 2011;24:163-5.

12. Jayaraj R, Megha P, Sreedev P. Organochlorine pesticides, their toxic effects on living organisms and their fate in the environment. Interdiscip Toxicol 2016;9:90-100.

13. Gray JM, Rasanayagam S, Engel C, Rizzo J. State of the evidence 2017: An update on the connection between breast cancer and the environment. Environ Health 2017; 16:94.

14. Wolff MS, Toniolo PG, Lee EW, Rivera M, Dubin N. Blood levels of organochlorine residues and risk of breast cancer. J Natl Cancer Inst 1993;85:648-52.

15. Olaya-Contreras P, Rodríguez-Villamil J, Posso-Valencia HJ, Cortez JE. Organochlorine exposure and breast cancer risk in Colombian women. Cad Saude Publica 1998; 14 Suppl 3:125-32.

16. Demers A, Ayotte P, Brisson J, Dodin S, Robert J, Dewailly E. Risk and aggressiveness of breast cancer in relation to plasma organochlorine concentrations. Cancer Epidemiol Biomarkers Prev 2000;9:161-6.

17. Gatto NM, Longnecker MP, Press MF, Sullivan-Halley J, McKean-Cowdin R, Bernstein L, et al. Serum organochlorines and breast cancer: A case-control study among African-American women. Cancer Causes Control 2007; 18:29-39.

18. Shakeel MK, George PS, Jose J, Jose J, Mathew A. Pesticides and breast cancer risk: A comparison between developed and developing countries. Asian Pac J Cancer Prev 2010; 11: 173-80.

19. Mathur V, Bhatnagar P, Sharma RG, Acharya V, Sexana R. Breast cancer incidence and exposure to pesticides among women originating from Jaipur. Environ Int 2002;28:331-6.

20. Gupta PK. Pesticide exposure - Indian scene. Toxicology 2004; 198:83-90.

21. Rusiecki JA, Baccarelli A, Bollati V, Tarantini L, Moore LE, Bonefeld-Jorgensen EC. Global DNA hypomethylation is associated with high serum-persistent organic pollutants in Greenlandic Inuit. Environ Health Perspect 2008;116:1547-52.

22. Eldakroory SA, Morsi DE, Abdel-Rahman RH, Roshdy S, Gouida MS, Khashaba EO, et al. Correlation between toxic organochlorine pesticides and breast cancer. Hum Exp Toxicol 2017;36:1326-34.

23. He TT, Zuo AJ, Wang JG, Zhao P. Organochlorine pesticides accumulation and breast cancer: A hospital-based case-control study. Tumour Biol 2017;39: 1010428317699114.

24. Wielsøe M, Kern P, Bonefeld-Jørgensen EC. Serum levels of environmental pollutants is a risk factor for breast cancer in Inuit: A case control study. Environ Health 2017; 16:56.

25. Høyer AP, Jørgensen T, Rank F, Grandjean P, Ahlborg U, Lipworth L, et al. Organochlorine exposures influence on breast cancer risk and survival according to estrogen receptor status: A Danish cohort-nested case-control study. BMC Cancer 2001;1:1-8.

26. Arrebola JP, Belhassen H, Artacho-Cordón F, Ghali R, Ghorbel H, Boussen $\mathrm{H}$, et al. Risk of female breast cancer and serum concentrations of organochlorine pesticides and polychlorinated biphenyls: A case-control study in Tunisia. Sci Total Environ 2015;520:106-13.

27. Ibarluzea JJ, Fernández MF, Santa-Marina L, Olea-Serrano MF, Rivas AM, Aurrekoetxea JJ, et al. Breast cancer risk and the combined effect of environmental estrogens. Cancer Causes Control 2004; 15:591-600.

\section{Second Opinion Service by five cancer experts}

Are you frustrated with patients seeking opinion in higher center?

Do you feel much time and money is lost in patients travelling to metro for second opinion?

Here is the solution of getting consolidated opinion from five cancer experts for your patient - without him having to leave your city. www.cancerexpert.in can help you

Ongoing clinical trials in oncology in India

Do you want to get updated about clinical trials ongoing in India? WhatsApp to 9869425694 to be included in the discussion group

Medic LAWgic - MedicoLegal Insights

If you are interested in joining WhatsApp discussion about medico legal aspects, please send request to 9869425694 